\title{
Hyperthermic Intraperitoneal Chemotherapy: A Critical Review
}

\author{
Wim Ceelen ${ }^{1,2, *}$, Jesse Demuytere ${ }^{1,2} \mathbb{D}$ and Ignace de Hingh ${ }^{3,4}$ \\ 1 Department of GI Surgery, Ghent University Hospital, 9000 Ghent, Belgium; jesse.demuytere@ugent.be \\ 2 Cancer Research Institute Ghent (CRIG), 9000 Ghent, Belgium \\ 3 Department of Surgery, Catharina Cancer Institute, PO Box 1350, 5602 ZA Eindhoven, The Netherlands; \\ ignace.d.hingh@catharinaziekenhuis.nl \\ 4 GROW—School for Oncology and Developmental Biology, Maastricht University, PO Box 616, \\ 6200 MD Maastricht, The Netherlands \\ * Correspondence: wim.ceelen@ugent.be; Tel.: +32-9332-6251
}

check for

updates

Citation: Ceelen, W.; Demuytere, J.; de Hingh, I. Hyperthermic Intraperitoneal Chemotherapy: A Critical Review. Cancers 2021, 13, 3114. https://doi.org/10.3390/ cancers13133114

Academic Editor: Oliver J. Ott

Received: 8 May 2021

Accepted: 16 June 2021

Published: 22 June 2021

Publisher's Note: MDPI stays neutral with regard to jurisdictional claims in published maps and institutional affiliations.

Copyright: (c) 2021 by the authors. Licensee MDPI, Basel, Switzerland. This article is an open access article distributed under the terms and conditions of the Creative Commons Attribution (CC BY) license (https:/ / creativecommons.org/licenses/by/ $4.0 /)$.
Simple Summary: Patients with cancer of the digestive system or ovarian cancer are at risk of developing peritoneal metastases (PM). In some patients with PM, surgery followed by intraperitoneal (IP) chemotherapy has emerged as a valid treatment option. The addition of hyperthermia is thought to further enhance the efficacy of IP chemotherapy. However, the results of recent clinical trials in large bowel cancer have put into question the use of hyperthermic intraperitoneal chemotherapy (HIPEC). Here, we review the rationale and current results of HIPEC for PM and propose a roadmap to further progress.

\begin{abstract}
With increasing awareness amongst physicians and improved radiological imaging techniques, the peritoneal cavity is increasingly recognized as an important metastatic site in various malignancies. Prognosis of these patients is usually poor as traditional treatment including surgical resection or systemic treatment is relatively ineffective. Intraperitoneal delivery of chemotherapeutic agents is thought to be an attractive alternative as this results in high tumor tissue concentrations with limited systemic exposure. The addition of hyperthermia aims to potentiate the anti-tumor effects of chemotherapy, resulting in the concept of heated intraperitoneal chemotherapy (HIPEC) for the treatment of peritoneal metastases as it was developed about 3 decades ago. With increasing experience, HIPEC has become a safe and accepted treatment offered in many centers around the world. However, standardization of the technique has been poor and results from clinical trials have been equivocal. As a result, the true value of HIPEC in the treatment of peritoneal metastases remains a matter of debate. The current review aims to provide a critical overview of the theoretical concept and preclinical and clinical study results, to outline areas of persisting uncertainty, and to propose a framework to better define the role of HIPEC in the treatment of peritoneal malignancies.
\end{abstract}

Keywords: peritoneal; HIPEC; intraperitoneal; drug transport

\section{Introduction}

Peritoneal metastases (PM) are a common manifestation of abdominal malignancies, most frequently occurring in patients with upper gastrointestinal, colorectal, and ovarian cancer [1-3]. Although less often, primary solid tumors outside the peritoneal cavity such as malignant melanoma, lung cancer, and lobular breast cancer may also metastasize to the peritoneum [4,5]. An increased awareness amongst physicians as well as the improvement of radiological techniques such as diffusion-weighted MRI have resulted in an increasing incidence of PM being reported in population-based studies in recent years. When taking all the origins together, PM pose a significant burden on current oncological care.

For long, it has been recognized that systemic treatment of PM appears to be less effective as compared to lung or liver metastases [6]. Poor vascularization of the peritoneal cavity may play a role, but the exact mechanisms underlying this phenomenon remain to 
be elucidated. As anticancer drugs are usually administered systemically exposing healthy tissue, their therapeutic index is limited. Some of these shortcomings can be addressed by local or locoregional delivery of chemotherapy. During this mode of anticancer therapy, drug is administered either through a feeding artery, or into an anatomical cavity. Locoregional drug delivery allows to administer a higher dose with less systemic toxicity. Examples include hepatic artery infusion and instillation in the peritoneum (intraperitoneal, IP), bladder (intravesical), brain ventricles (intrathecal), and chest cavity (intrapleural).

Intraperitoneal chemotherapy takes advantage of the large surface area of the peritoneum (approximately $2 \mathrm{~m}^{2}$ ) to enable mass transfer either from the peritoneal cavity to the systemic circulation (drug therapy), or vice versa (dialysis). The origins of the peritoneal route of drug delivery can be traced back to the eighteenth century: in 1744, the English surgeon Christopher Warrick, instilled a mixture of 'Bristol water' and Bordeaux wine in the peritoneal cavity of a patient with intractable ascites, apparently with great success [7]. There was some enthusiasm during the first half of the twentieth century for IP administration of radioactive gold $\left({ }^{198} \mathrm{Au}\right)$ in the adjuvant and palliative treatment of ovarian cancer, but significant morbidity was observed [8]. Also, intraperitoneal radioactive chromic phosphate $\left({ }^{32} \mathrm{P}\right)$ administration was attempted for ovarian cancer, but this led to significant complications and resulted in inhomogeneous drug distribution [9].

The interest in intraperitoneal drug delivery (IPDD) was rekindled with the publications of Dedrick in the 1970s. He proposed a theoretical framework for IPDD based on the pharmacokinetic (PK) advantage that results from the fact that systemic drug clearance is much faster compared to peritoneal clearance. As a result, IP drug can be administered at a higher dose with low systemic exposure and toxicity [10]. Of note, Dedrick was also one of the first authors to emphasize that despite the obvious PK advantage of IPDD, the resulting tissue penetration depth is very limited [11].

The use of hyperthermia to treat cancerous growths dates from several millennia ago and continues to find applications in modern medicine. The concept of combining IPDD with hyperthermia as a hyperthermic IP chemoperfusion (HIPEC) was first studied in an animal model in 1974 by Euler [12]. The first clinical use of HIPEC was reported in 1980 by Spratt et al., who performed hyperthermic chemoperfusion with thiotepa in a patient with pseudomyxoma peritonei (PMP) [13].

In the following decades, HIPEC was introduced in the treatment of peritoneal metastases from a variety of primary malignancies and in primary peritoneal malignancies including peritoneal mesothelioma. Long surrounded by skepticism, HIPEC is now offered at hundreds of treatment centers worldwide [14]. Nevertheless, the efficacy and safety of HIPEC remain debated and hamper the universal acceptance by the oncology community. Proponents will argue that the addition of HIPEC was recently shown to prolong survival in ovarian cancer in a randomized clinical trial (RCT) but criticism was undoubtedly fueled by negative results of RCTs in patients with colorectal cancer (CRC) PM [15].

The aims of this review are to provide a critical overview of the theoretical concept and preclinical and clinical study results, to outline areas of persisting uncertainty, and to propose a framework to better define the role of HIPEC in the treatment of peritoneal malignancies.

\section{Basic Concepts}

\subsection{Pharmacokinetic Behavior and Drug Tissue Transport after Intraperitoneal Chemotherapy}

The pharmacokinetic rationale for IPDD is based mainly on the presence of the peritoneal-plasma barrier [16]. The resulting (PK) advantage can be expressed as the parameter $R_{d}$, calculated as $\left(C_{P} / C_{B}\right) I P /\left(C_{P} / C_{B}\right) I V$ where $C_{P}$ and $C_{B}$ represent the peritoneal and blood concentrations, respectively (Figure 1). The pharmacokinetics of IPDD is usually described using compartmental models, which consist of a systemic and a peritoneal compartment. These idealized compartments are separated by the peritoneal-plasma barrier, which is characterized by a permeability-area (PA) product. Based on experimental correlations of measured drug clearance with molecular properties, it was estimated that the PA is inversely proportional to the square root of the molecular weight of the drug [17]. 


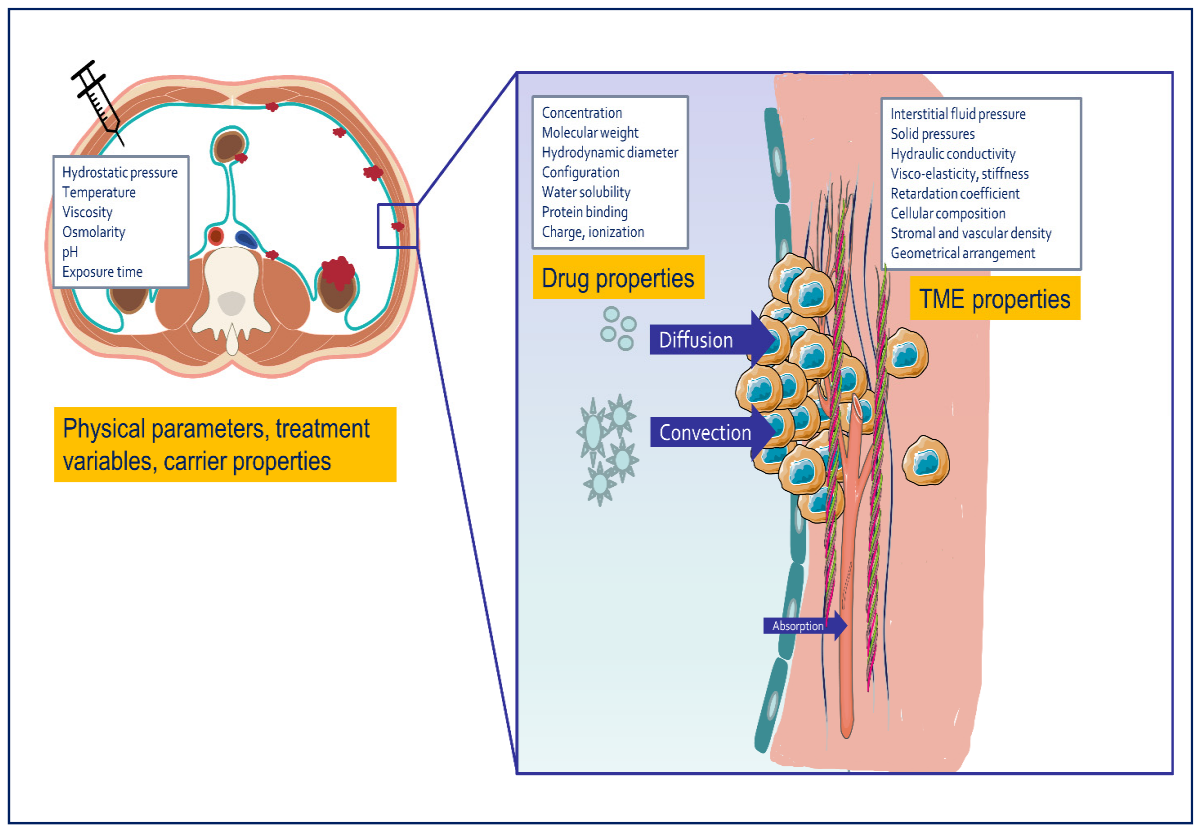

Figure 1. Overview of relevant mechanisms and variables that affect tissue transport after intraperitoneal drug delivery. Drug transport is driven by convection (pressure gradient) and by diffusion (concentration gradient). The ratio of convective/diffusive transport is larger for large or nanosized compounds.

Intraperitoneal drug delivery allows to reach a high IP drug concentration. However, the anticancer efficacy depends on the tissue drug concentration. Therefore, the extent of mass transport into the tissue is an essential parameter that determines the efficacy of IPDD. Simulations and experimental studies consider tumor tissue as a homogeneous (isotropic) porous medium. Two major mechanisms determine the transport of drug into tumor tissue: convection or bulk fluid flow, which is driven by a pressure gradient, and diffusion, resulting from a concentration gradient. In reality, both mechanisms occur simultaneously, and the ratio of convective over diffusive transport is quantified as the Péclet number. The Péclet number is low for small molecules (diffusion dominates) and higher for large compounds such as antibodies or nanoparticles, for which tissue penetration mainly depends on a pressure difference.

\subsubsection{Convection}

During HIPEC, the extent of convective drug transport is proportional to the difference in pressure between the fluid filled peritoneal cavity, and the stromal tissue pressure. Since chemotherapeutics will interact with cellular and stromal structures, the velocity of the compound is always slower than that of the carrier fluid in which it is dissolved. The ratio of both velocities is termed the retardation or hindrance coefficient. The hydrostatic pressure exerted by the intraperitoneal fluid column can be estimated as $10-20 \mathrm{~cm} \mathrm{H}_{2} \mathrm{O}$ $(7.4-14.8 \mathrm{~mm} \mathrm{Hg})$. The tissue pressure that resides in the peritoneal cancer tissue has never been measured clinically, but results from preclinical experiments and numerical simulations suggest that it is much higher compared to normal tissue. First, tumor tissue is characterized by an elevated interstitial fluid pressure (IFP) caused by increased blood flow, 'leaky' capillaries, and deficient lymphatic drainage [18]. Second, tumor tissue is associated with elevated solid stress, arising from different sources [19]. External solid stress is exerted on the tumor as it grows and compresses the surrounding tissue. Swelling solid tissue stress is the result of electrostatic repulsion between negatively charged stromal components such as hyaluronic acid [20]. A third component is residual solid tissue stress, which represents the stored elastic energy which can be observed when cutting into a solid tumor: this leads to its bulging and expansion. Pressure driven (convective) drug transport also depends on the hydraulic conductivity of the tissue, which is affected by the viscosity of the interstitial fluid and by mechanical stiffness of the tumor stroma [21]. 


\subsubsection{Diffusion}

According to Fick's law, diffusive mass transport is driven by a concentration gradient. In addition, the rate of drug diffusion depends on temperature, physicochemical drug properties, and on the stromal architecture [22]. Relevant drug properties include its molecular weight, hydrodynamic size, charge, and configuration. Important properties of the stroma or extracellular matrix (ECM) that affect drug diffusion are cellular composition, density, stiffness, visco-elasticity, and geometrical fiber arrangement [23]. In cancer tissue, there is increased deposition of collagen I, resulting in increased stiffness or rigidity compared to normal tissue. Also, tumors overexpress the collagen cross-linking enzyme lysyl oxidase (LOX), which further increases stromal stiffness [24]. Also, the geometric arrangement of collagen fibers affects drug diffusion: experimental studies show that fibers that are oriented tangentially from the tumor surface direct drug diffusion away from the tumor, while the opposite occurs when fibers are radially aligned [25].

\subsection{Penetration Depth after IPDD}

An important limitation of IPDD is the very limited penetration distance in tumor tissue, which is a few millimeters at most, depending on drug, treatment, and tissue properties [26]. This is explained by the elevated pressure characterizing the biophysical TME, and by the very low hydraulic conductivity of tumor tissue, which is typically in the range of $10^{-15}$ $10^{-14} \mathrm{~m}^{2} / \mathrm{pa} \cdot \mathrm{s}$ in colorectal PM as measured using modified Ussing chambers. Only limited clinical data are available on tissue penetration after IPDD. Several authors have reported drug concentrations in tissue homogenates after HIPEC, but this is a poor substitute for the actual penetration distance. Preliminary data from a study comparing normothermic versus hyperthermic chemoperfusion with cisplatin for ovarian cancer (NCT02567253) show that platinum penetrates normal stroma much easier than the cancer nodules (Figure 2). As a consequence, numerous physical, chemical, and pharmacological approaches have been tested preclinically in order to enhance drug penetration after IPDD, and the interested reader is referred to a recent review on this topic [27]. In clinical trials, several approaches are being tested that target matrix deposition, matrix remodeling, and cell-matrix interactions in solid cancers [28]. However, none of these trials use IPDD for PM.

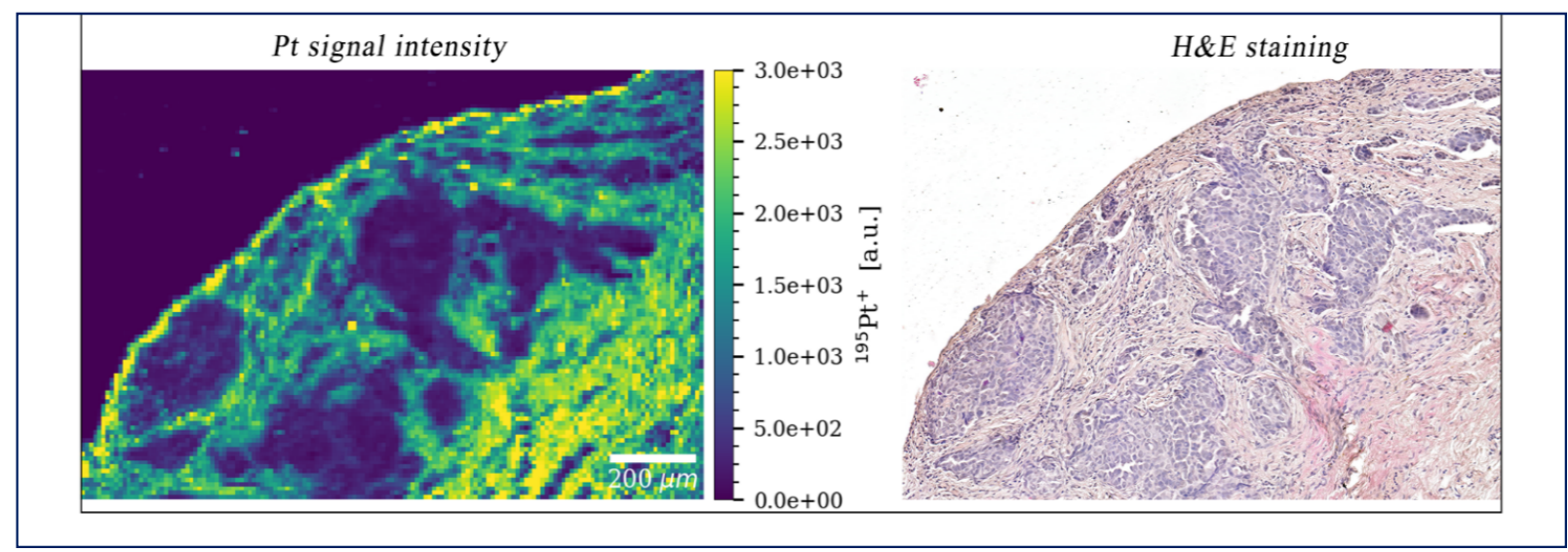

Figure 2. Platinum $(\mathrm{Pt})$ penetration after HIPEC using cisplatin in a patient with peritoneal metastases from ovarian cancer. When comparing Pt penetration with histology, it is obvious that Pt penetrates the stroma much more efficiently compared to the nests of cancer cells.

\subsection{Use of Hyperthermia}

The use of hyperthermia in oncology has a long history and is based on several parallel observations. First, the use of hyperthermia is selectively lethal for malignant cells [29]. Second, the effects of heat can be synergistic with those of other anticancer treatments, including chemotherapy and radiotherapy [30]. There is considerable heterogeneity in 
the extent, timing, and underlying mechanisms of thermal enhancement of chemotherapy. Synergism with heat is particularly evident for the platinum compounds and mitomycin C. However, other agents such as the taxanes and the antimetabolites do not show thermal enhancement. Third, hyperthermia improves tissue perfusion and oxygenation, and may enhance tissue penetration. In a rodent model of colorectal peritoneal cancer, Los and coworkers found significantly higher tumor platinum concentrations when IP cisplatin was combined with regional hyperthermia $\left(41.5^{\circ} \mathrm{C}\right)$ [31]. Other drugs showing increased tumor penetration when combined with hyperthermia include carboplatin, oxaliplatin, and doxorubicin [32,33]. Of note, many of the in vitro studies that have aimed to establish thermal enhancement of chemotherapy have used temperatures, exposure times, and drug concentrations that are not clinically relevant or achievable. Helderman and coworkers recently performed a series of in vitro experiments using clinically relevant conditions (38-43 ${ }^{\circ} \mathrm{C}$ for $60 \mathrm{~min}$ ) in several 2D and 3D human colorectal cancer cultures [34]. They showed that thermal enhancement of cytotoxicity is highly dependent on the cell line and on the drug used: thermal enhancement was evident for oxaliplatin and cisplatin, but not for mitomycin C, carboplatin, or 5-FU. Interestingly, hyperthermia may diminish the systemic toxicity of some drugs, such as doxorubicin and cyclophosphamide by increasing their alkylation and/or excretion [35]. Besides the choice of drug, also length of the exposure to hyperthermia might play a crucial role. This was recently investigated using patient-derived organoids from colorectal cancer PM. In this study by Forsythe, low dose heated oxaliplatin $\left(200 \mathrm{mg} / \mathrm{m}^{2}\right)$ for $200 \mathrm{~min}$ appeared to be more effective in terms of cytotoxicity than a higher dose of oxaliplatin $\left(460 \mathrm{mg} / \mathrm{m}^{2}\right)$ for only $30 \mathrm{~min}$ [36].

The ideal target temperature of HIPEC is unknown. In vitro, DNA repair is inhibited at a temperature $>41^{\circ} \mathrm{C}$, but the relationship between temperature and anticancer efficacy in vivo is not known. Also, due to the heat sink effect of the tumor blood vessels, the actual tissue temperature that can be reached is lower than that of the heated IP solution. Hyperthermia elicits the expression of heat shock proteins (HSP's), which were shown to exert anti-apoptotic and proliferative effects, and to induce resistance to chemotherapy $[37,38]$. Also, temperatures above $41^{\circ} \mathrm{C}$ may cause scald injury to the peritoneum, which is already extensively damaged by the CRS [39].

There is only one clinical study in the 'prophylactic' setting that has compared normothermic with hyperthermic chemoperfusion. Yonemura and coworkers randomly allocated patients with T2-4 gastric cancer without peritoneal metastases who underwent gastrectomy with extended lymphadenectomy to either surgery alone $(N=47)$, surgery with HIPEC (mitomycin $C$ and cisplatin, $N=48$ ), or surgery with normothermic chemoperfusion $(N=44)$ [40]. In univariate analysis, overall survival was better in the hyperthermic group compared to the two other groups. In a multivariable (Cox) model, the hazard ratio for death of normothermic versus hyperthermic chemoperfusion was 1.77 (95\% confidence interval $0.91-3.42, P=0.092)$. The methodological quality of this randomized trial (according to the CONSORT guidelines) was, however, moderate.

In the era of immune therapy, there is renewed interest in the potential immune stimulating effects of hyperthermia [41]. Hyperthermia leads to immunogenic cell death by secretion of damage associated molecular patterns (DAMPs) including calreticulin, ATP, high mobility group B1 (HMGB1), and heat shock proteins 90 and 70. These patterns may activate antigen presenting cells and mobilize an effective $\mathrm{T}$ cell mediated immune response. Also, hyperthermia may reverse the 'cold' tumor microenvironment (TME) observed in most PM to a highly immunogenic TME, which sensitizes tumors to immune checkpoint inhibition. In studies that combine radiotherapy with external hyperthermia, immune modulating effects were observed, leading to an abscopal therapy response [42]. Others have shown, however, potentially adverse effects of local heating on overall tumor immunity [43]. HSPs s can promote cancer growth and malignant behavior by the induction of extracellular matrix remodeling, resistance to apoptosis, epithelial to mesenchymal transition, tumor angiogenesis, and metastasis [44]. A recent phase-2 clinical trial investigated the potential additional value of autologous tumor antigen-loaded $\alpha \mathrm{DC} 1$ vaccine in 
patients undergoing CRS and HIPEC for peritoneal metastases. The therapy appeared to be well tolerated by patients but the effect of vaccination on median survival appeared to be limited and it was concluded that this was not a good strategy to pursue [45].

Very little is known on the effect of HIPEC on the TME of PM, and on the peritoneal immune environment. Franko and coworkers sampled peritoneal fluid during HIPEC procedures at different time intervals between 0 and $90 \mathrm{~min}$ [46] They did not observe significant changes in the number of peritoneal NK cells, CD4/CD8 ratio, or granulocyte/lymphocyte ratio during the course of HIPEC.

\section{Clinical Implementation of Hyperthermic Intraperitoneal Drug Delivery}

The basic setup used for HIPEC treatment consists of one or more inflow- and outflow tubes and temperature probes, one or more roller pumps, and a heating element. Several HIPEC devices are commercially available. There is considerable heterogeneity in the procedural parameters that are used to administer HIPEC: drug type and dose regimen, carrier solution, target temperature, treatment duration, and delivery technique all vary substantially according to local preference [47]. As a result, many different HIPEC-regimens are currently used and standardization is sparse, hampering pooling of outcome data [48].

\subsection{Choice and Combination of Chemotherapy}

Ideally, chemotherapy drugs for HIPEC should have the following properties: a favorable pharmacokinetic profile, no cell cycle specificity, and absence of local peritoneal toxicity. Unfortunately, all chemotherapeutics currently administered during HIPEC are used off label. In colorectal cancer, debate persists on the use of oxaliplatin versus mitomycin C for HIPEC. Results from retrospective studies are difficult to interpret due to differences in clinical and treatment parameters [49]. A prospective randomized trial in appendiceal cancer showed that compared to mitomycin C, the use of oxaliplatin for HIPEC was associated with a better safety and quality of life profile [50,51]. However, oxaliplatin as a HIPEC agent failed in recent randomized trials in colorectal cancer. Possibly, additional factors such as choice of carrier solution, target temperature, and treatment duration are important determinants of the efficacy of oxaliplatin, as recently demonstrated in organoid models [36,52].

Although it seems intuitively appealing to combine drugs for HIPEC, several caveats should be taken into consideration. First, unsuspected chemical or physical incompatibilities may exist that preclude the administration of two or more drugs IP in the same solution. Second, when toxicity occurs, it will be problematic to find out which agent is responsible for which observed toxicity. Third, prospective clinical trials do not support the use of multi-agent HIPEC regimens. Quénet and coworkers showed that, compared to HIPEC with oxaliplatin alone, the addition of irinotecan significantly increased the complication rate, but did not benefit recurrence-free or overall survival [53].

\subsection{Open Versus Closed Abdomen Perfusion}

Chemoperfusion with the skin and/or fascial layer closed theoretically prevents contamination of the OR environment and heat loss and may enhance convection driven tumor chemotherapy penetration due to increased IP pressure. The open technique ('coliseum'), on the other hand, allows to manually stir the abdominal contents in order to ensure homogeneous drug and temperature distribution. Prospective comparative studies are lacking, but retrospective data suggest that both techniques are comparable in terms of intraoperative hemodynamics and postoperative morbidity [54,55]. Recent developments include the use of $\mathrm{CO}_{2}$ recirculation and laparoscopy assisted HIPEC [56,57].

\section{Clinical Results of HIPEC}

The results of the most important randomized clinical trials that have investigated HIPEC are summarized in Table 1. 
Table 1. Overview of randomized trials comparing surgery combined with HIPEC versus surgery alone.

\begin{tabular}{|c|c|c|c|c|c|c|}
\hline Tumor & Study, Year & Inclusion & Primary Endpoint & Treatment and N Randomized & Results & $\begin{array}{l}95 \% \text { CI of Effect } \\
\text { and } P \text { Value }\end{array}$ \\
\hline \multirow[t]{5}{*}{$\begin{array}{l}\text { Colorectal } \\
\text { cancer }\end{array}$} & $\begin{array}{l}\text { Verwaal [58] (2003, } \\
\text { updated 2008) }\end{array}$ & $\begin{array}{c}\text { Histologically proven PM, age }<71 \text { yrs, } \\
\text { no distant metastasis }\end{array}$ & Disease specific survival & $\begin{array}{l}\text { Chemotherapy alone (5-FU-LV) } N=51 \\
\text { CRS and HIPEC (MMC, } 90 \mathrm{~min}) N=54\end{array}$ & $\begin{array}{l}12.6 \mathrm{~m} \\
22.2 \mathrm{~m}\end{array}$ & $P=0.028$ \\
\hline & Prodige 7 (2021) [15] & Histologically proven PM, PCI $\leq 25$ & Overall survival & $\begin{array}{c}\text { CRS } N=132 \\
\text { CRS and HIPEC }(\mathrm{OX}, 30 \mathrm{~min}) N=133\end{array}$ & $\begin{array}{l}41.2 \mathrm{~m} \\
41.7 \mathrm{~m}\end{array}$ & $\begin{array}{l}\text { HR } 0.63-1.58 \\
\quad P=0.99\end{array}$ \\
\hline & $\underset{[59]}{\operatorname{COLOPEC~(2019)}}$ & $\begin{array}{l}\text { Clinical or pathological } \mathrm{T}_{4} \mathrm{~N}_{0-2} \mathrm{M}_{0} \text {-or } \\
\text { perforated colon cancer }\end{array}$ & $\begin{array}{l}\text { Peritoneal metastasis } \\
\text { free survival at } \\
18 \text { months }\end{array}$ & $\begin{array}{l}\text { Adjuvant HIPEC }(\mathrm{OX}, 30 \mathrm{~min}) \text { and } \\
\text { adjuvant chemotherapy } N=102 \\
\text { Adjuvant chemotherapy } N=102\end{array}$ & $\begin{array}{l}80.9 \% \\
76.2 \%\end{array}$ & $P=0.28$ \\
\hline & $\begin{array}{l}\text { PROPHYLOCHIP } \\
\text { (2020) [60] }\end{array}$ & $\begin{array}{l}\text { Synchronous and resected PM, resected } \\
\text { ovarian metastases, perforated tumor }\end{array}$ & Disease free survival & $\begin{array}{c}\text { Adjuvant chemotherapy and HIPEC } \\
\text { (OX } \pm \text { IRI, } 30 \text { min) } N=75 \\
\text { Adjuvant chemotherapy } N=75\end{array}$ & $\begin{array}{l}44 \% \\
53 \%\end{array}$ & $\begin{array}{l}\text { HR } 0.61-1.56 \\
\quad P=0.82\end{array}$ \\
\hline & Rovers (2021) [61] & $\begin{array}{c}\text { Histologically proven isolated } \\
\text { resectable PM }\end{array}$ & $\begin{array}{l}\% \text { complete } \mathrm{CRS} / \% \\
\text { Clavien-Dindo } \geq \text { grade } \\
3 \text { morbidity }\end{array}$ & $\begin{array}{c}\text { Perioperative chemotherapy and } \\
\text { CRS-HIPEC (MMC, } 90 \text { min or OX, } 30 \mathrm{~min} \text { ) } \\
N=40 \\
\text { CRS and HIPEC alone } N=40\end{array}$ & $\begin{array}{l}89 \% / 22 \% \\
86 \% / 33 \%\end{array}$ & $\begin{array}{c}\text { RR 0.88-1.23, } \\
P=0.74 / 0.31-1.37, \\
P=0.25\end{array}$ \\
\hline \multirow[t]{3}{*}{ Ovarian cancer } & Spiliotis (2015) [62] & Recurrent EOC & Overall survival & $\begin{array}{l}\text { CRS and HIPEC (CIS or DOX with PTX or } \\
\text { MMC, } 60 \text { min) } N=60 \\
\text { CRS alone } N=60\end{array}$ & $\begin{array}{l}26.7 \mathrm{~m} \\
13.4 \mathrm{~m}\end{array}$ & $P=0.006$ \\
\hline & OVHIPEC (2018) [63] & $\begin{array}{l}\text { EOC with at least stable disease after } \\
\text { three cycles of carboplatin-PTX }\end{array}$ & Recurrence free survival & $\begin{array}{c}\text { Interval CRS and HIPEC (CIS, } 90 \mathrm{~min}) \\
N=122 \\
\text { Interval CRS alone } N=123\end{array}$ & $\begin{array}{l}14.2 \mathrm{~m} \\
10.7 \mathrm{~m}\end{array}$ & $\begin{array}{l}\text { HR } 0.50-0.87 \\
\quad P=0.003\end{array}$ \\
\hline & Zivanovic (2021) [64] & Recurrent EOC & $\begin{array}{l}\text { Proportion free of } \\
\text { progression at } 24 \text { months } \\
\text { ('pick the winner') }\end{array}$ & $\begin{array}{c}\text { CRS and HIPEC (Carboplatin, } 90 \mathrm{~min} \text { ) } \\
\text { followed by } 5 \text { cycles of Carboplatin based } \\
\text { IV chemotherapy } N=49 \\
\text { CRS alone followed by } 6 \text { cycles of } \\
\text { Carboplatin based IV chemotherapy } N=49\end{array}$ & $\begin{array}{l}16.3 \% \\
24.5 \%\end{array}$ & $\begin{array}{l}\text { Not applicable (no } \\
\text { winner } \\
\text { determined) }\end{array}$ \\
\hline
\end{tabular}

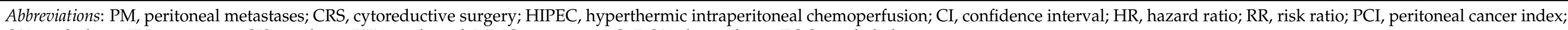
OX, oxaliplatin; IRI, irinotecan; CIS, cisplatin; PTX, paclitaxel; MMC, mitomycin C; DOX, doxorubicin; EOC, epithelial ovarian cancer. 


\subsection{Ovarian Cancer}

The majority of epithelial ovarian cancer (EOC) patients presents with peritoneal metastases and around 75\% will relapse in the peritoneal cavity after successful first line treatment. Therefore, EOC appears to be the ideal candidate for IPDD and remains the best studied indication. In addition, serous primary peritoneal cancer is regarded as sharing many molecular and clinical features with EOC and is treated similarly [65]. The multicenter randomized OVHIPEC trial investigated the additional benefit of cisplatin based HIPEC to cytoreductive surgery (CRS) after neoadjuvant chemotherapy (NACT) in patients with primary EOC who were initially not eligible for CRS due to extensive peritoneal involvement. It was found that the addition of HIPEC to interval CRS resulted in a significantly better progression free survival, while overall survival increased from 33.9 to 45.7 months [63]. Addition of HIPEC in these patients did not result in more postoperative complications, did not negatively affect the quality of life and appeared to be cost-effective $[66,67]$. Based on these results, the current guidelines of the US National Comprehensive Cancer Network (NCCN) indicate that HIPEC can be considered for all patients with stage III EOC for whom NACT and interval CRS is performed [68,69]. A second smaller trial, published as abstract only, used a lower IP cisplatin dose, included primary as well as interval CRS patients, and failed to demonstrate a significant difference in PFS [70]. In recurrent EOC, the results of a small RCT showed a superior overall survival after CRS and HIPEC versus surgery alone (26.7 versus 13.4 months, $P=0.006$ ) [62] However, the methodological quality of that trial was only moderate. A recent randomized phase II trial assigned recurrent EOC patients to either CRS and HIPEC (Carboplatin $800 \mathrm{mg} / \mathrm{m}^{2}$ for $90 \mathrm{~min}$ ) or CRS alone, followed by five or six cycles of postoperative IV carboplatin-based chemotherapy, respectively [64]. Based on a 'pick-the-winner' design, an arm would be considered superior if at least 17 out of 49 patients were without progression at 24 months follow-up. The results showed that at 24 months, eight patients $(16.3 \%)$ in the HIPEC arm and $12(24.5 \%)$ in the CRS alone arm were free of progression, indicating that the addition of HIPEC with Carboplatin did not lead to superior outcomes.

Currently, the international OVHIPEC-2 consortium is investigating the role of HIPEC in patients with FIGO stage III ovarian cancer who are treated with primary CRS. In total, 538 patients will be randomized to CRS with or without HIPEC [71]. A French multicenter randomized trial (CHIPOR; ClinicalTrials.gov identifier: NCT01376752) was initiated in 2011 and compares CRS alone with CRS plus HIPEC in patients with recurrent ovarian cancer. Interestingly, the recently initiated Australian HyNOVA (Hyperthermic versus Normothermic intraperitoneal chemotherapy following interval cytoreductive surgery for stage III epithelial OVArian cancer) will compare interval debulking and chemoperfusion with cisplatin $\left(100 \mathrm{mg} / \mathrm{m}^{2}, 90 \mathrm{~min}\right)$ at two different temperatures: $42.0^{\circ} \mathrm{C}$ and $37.0^{\circ} \mathrm{C}$ [72]. Currently, therefore, the available evidence supports the use of HIPEC in association with interval CRS in stage III EOC. The results of ongoing trials are awaited to establish its role in primary CRS and recurrent cases.

\subsection{Colorectal Cancer}

In 2003, a randomized clinical trial showed that CRS and HIPEC (90 min, mitomycin-C $35 \mathrm{mg} / \mathrm{m}^{2}$ ) improved survival in patients with colorectal peritoneal metastases as compared to palliative surgery and systemic treatment alone (22 versus 12 months respectively) [73]. Ever since, numerous non-controlled studies have shown that long-term survival can be obtained with CRS and HIPEC with median survivals ranging from 14.6 to 60.1 months according to a recent review [74]. Although the treatment-related mortality in the trial by Verwaal was as high a $8 \%$, this has decreased significantly with increasing experience and is currently as low as $1-2 \%$ in most centers [75].

A recently published French multicentre study compared CRS alone with CRS combined with short duration (30 minutes) oxaliplatin $\left(460 \mathrm{mg} / \mathrm{m}^{2}\right)$ based HIPEC in colorectal PM (PRODIGE 7/ACCORD 15, NCT00769405) [15]. Interestingly, the addition of HIPEC did not improve OS in this trial, but did increase 90 day morbidity. This raises the question 
concerning the value of HIPEC in addition to complete CRS in colorectal cancer PM. A possible explanation for the lack of efficacy of the oxaliplatin-based regimen in the PRODIGE 7 trial may be the selection of patients as these were only included after a minimum of 6 months of systemic therapy. Such therapy was oxaliplatin-based in the majority of patients and this may have resulted in an acquired resistance of the peritoneal metastases against IP oxaliplatin as was recently demonstrated in a pre-clinical study [76]. Also, patient-derived organoids from colorectal peritoneal metastases appear to be resistant to heated oxaliplatin in a dosage similar to the one used in the PRODIGE7 protocol [77].

Another topic of debate is whether systemic treatment, either neo-adjuvant, adjuvant or both should be part of the initial treatment strategy. Although peri-operative treatment was part of the PRODIGE7 study protocol and is practised widely around the world, highlevel evidence to support this practice is currently lacking $[78,79]$. In a recent retrospective comparative cohort study, no beneficial effect of peri-operative systemic therapy was shown after complete CRS and HIPEC [80]. In contrast, a large population based study including 393 patients undergoing CRS and HIPEC revealed a benefit of adjuvant systemic treatment as compared to standard follow up alone after propensity score matching. The value of perioperative chemotherapy is currently investigated in the international multicenter randomized CAIRO6-trial [81].

Besides a role for HIPEC in the treatment of established PM, also the role of 'prophylactic' two randomized trials have evaluated the use of HIPEC with oxaliplatin in patients at high risk of peritoneal recurrence (i.e., perforated tumors, pT4 tumors, minimal PM resected at the time of primary surgery, and ovarian (Krukenberg) metastases). Both the French ProphyloChip (NCT01226394) and the Dutch COLOPEC (NCT02231086) randomized trials did not meet their primary endpoint (three year disease free survival and peritoneal metastasis free-survival at 18 months, respectively) although long term results are awaited [82,83]. As also in these trials a short course (30 min) high-dosed oxaliplatin HIPEC regimen was used, questions were raised on the efficacy of IP oxaliplatin using this regimen [52]. A similar study of prophylactic HIPEC by the National Cancer Institute (NCT01095523) has been withdrawn [84].

\subsection{Pseudomyxoma Peritonei}

Appendiceal mucinous neoplasms represent a rare, histologically heterogeneous entity including low-grade appendicular neoplasm (LAMN), high-grade appendicular neoplasm (HAMN) and mucinous appendicular adenocarcinoma [85-87]. Ruptured low grade tumors may cause progressive accumulation of mucinous ascites and result in the pseudomyxoma peritonei (PMP) syndrome, which is a clinical and radiological phenotype rather than a histopathological diagnosis [88]. Encouraging survival results have been achieved in patients with PMP using cytoreductive surgery and HIPEC [89-91]. A recent international registry of over 2000 patients undergoing CRS and HIPEC for PMP showed a median survival of 16.3 years and a 10 year survival of $63 \%$ [92].

Recently, an international cohort study was published including 1924 patients with PMP, investigating the outcome after CRS with or without HIPEC [93]. It was found that the addition of HIPEC after CRS was associated with a significantly better overall survival as compared to CRS alone with a 5-year overall survival of $58 \%$ versus $46.2 \%$ respectively. The addition of HIPEC did not result in more post-operative complications. Therefore, CRS and HIPEC is proposed as the standard of care in patients with low grade appendiceal neoplasms associated with PMP [94]. Nevertheless, others argued that the favorable outcome achieved in PMP results from a favorable tumor biology and complete surgical removal rather than from the addition of HIPEC [95].

\subsection{Gastric Cancer}

The risk of peritoneal metastasis in gastric cancer is approximately $40 \%$, with almost $30 \%$ of patients presenting with peritoneal metastases at the time of diagnosis [2]. In the 
Far East (primarily Japan), promising results were obtained using prolonged IP taxane based chemotherapy in PM from gastric cancer PM [96,97].

Meta-analyses of small RCT's and non-controlled trials show a potential benefit of HIPEC in gastric cancer patients with positive cytology and without extensive nodal disease $[98,99]$. A recent propensity score adjusted comparison of CRS alone versus CRS with HIPEC in patients with PM from gastric cancer suggests that the addition of HIPEC results in a significant improvement of recurrence-free and overall survival [99]. Randomized trials were initiated to test the efficacy of HIPEC in gastric cancer with PM in the Netherlands (PERISCOPE II, NCT03348150), France (GASTRICHIP, NCT01882933), and China (NCT02356276). The initial results of the PERISCOPE-trial aimed at dosefinding were recently published. Although the amount of serious adverse events in the trial was high (17 out of 25 patients), it was shown that HIPEC with a dose of $50 \mathrm{mg} / \mathrm{m}^{2}$ intraperitoneal docetaxel appeared to be feasible [100] Survival data from that trial are currently awaited.

\subsection{Other Intra-Abdominal Cancers}

In patients with epitheloid malignant peritoneal mesothelioma, encouraging results were observed using CRS and HIPEC. A recent systematic review of six published studies including 240 patients showed a median survival ranging from 34 to 92 months [101]. Other peritoneal malignancies that were treated with IPDD include small bowel adenocarcinoma, peritoneal sarcomatosis, and desmoplastic small round cell tumors [102,103].

\section{Addressing Current Limitations of HIPEC: The Road to Progress}

\subsection{Development of Novel Anticancer Compounds and Carriers}

The main current limitation of HIPEC is that none of the currently used drugs were developed for intraperitoneal administration. Toxic effects of chemotherapy or the carrier solution on mesothelial integrity may offset anticancer efficacy. Also, HIPEC is performed only once, and treatment duration is typically short. Data from in vitro experiments suggest, that upon exposure to hyperthermia, the observed decrease in cancer cell survival decreases exponentially with longer treatment duration [104]. Also, simulations based on experimental data show that the response of cancer cell lines to chemotherapy depends not only on cell cycle phase specificity, cell cycle time, and drug concentration, but also on treatment duration [105]. Emerging approaches to extend treatment duration are the development of nanoparticles and prolonged delivery formulations such as hydrogels and drug loaded textiles [106]. While these may not be easily administered as a hyperthermic chemoperfusion, they may be combined with external sources of hyperthermia such as radiofrequency or with photothermal activation [107-110].

\subsection{Improved Heat Delivery Methods}

Homogeneous tissue heating is impeded by insufficient and preferential fluid flow and heat sink effects. Recently, studies based on computational fluid dynamics (CFD) were used to simulate fluid flow, temperature, and drug distribution to predict the influence of location and number of catheters, flow alternations, and flow rate [111]. The results of these studies, combined with adequate thermometry methods, may allow to improve spatial homogeneity of heat and drug in the peritoneal cavity.

\subsection{Clinically Relevant Preclinical Models}

HIPEC treatment was introduced in clinical practice in the absence of solid preclinical foundations. Given the challenging results of HIPEC in CRC, there is a need for clinically relevant, reproducible, and high throughput models to study the immune and anticancer effects of HIPEC in a systematic way. Several groups have established mouse HIPEC models, which offer the advantage of antibody availability and the potential to use human cell lines $[112,113]$. Recent developments include the use of patient derived organoids and 
'organs on a chip' in order to study the effects of hyperthermia combined with anticancer agents using patient derived tissue $[78,114,115]$.

\subsection{Elucidation of the Tumor Microenvironment and the Peritoneal Ecosystem}

It is increasingly evident that the behavior and treatment response of solid tumors is largely dictated by its biophysical, cellular, and molecular environment. This environment is radically different between primary tumors and their associated PM. Therefore, unraveling of the PM cascade and understanding the PM-associated tumor microenvironment (TME) are priorities for future research [116]. Furthermore, the immune contexture of $\mathrm{PM}$ and the peritoneal ecosystem, and how both are affected by extensive surgery, IP chemotherapy, and hyperthermia are barely studied and need to be characterized in detail.

\subsection{High Quality Clinical Trials}

After a long period of skepticism, HIPEC has gathered significant momentum over the past years, with 121 centers offering the treatment in the US alone in November 2019 [114]. In stark contrast, only a handful of RCTs has studied the efficacy of HIPEC. The obstacles faced by surgeon initiated trials are well known: perceived lack of equipoise, lack of training in clinical trial methodology, learning curve effects, and lack of funding [115]. Although the RCT remains the gold standard, possible alternative approaches that allow to facilitate gathering evidence on HIPEC include pragmatic trials, register based trials, patient preference trials, and adaptive (Bayesian) trial designs [117].

\section{Conclusions}

There are sound theoretical arguments that favor the incorporation of HIPEC in a multimodal strategy for patients with PM. Its current place remains, however, uncertain due to the significant variability in the drugs and methods used to deliver HIPEC. Also, results from clinical trials are inconsistent. Further development of HIPEC will require a better understanding of how surgery and HIPEC affect the tumor TME and peritoneal ecosystem. In addition, the role of treatment variables such as chemoperfusion temperature, HIPEC duration, and chemotherapeutic drug(s) need to be established. At the same time, efforts should be directed to the development of novel IP compounds and delivery systems, and to the expansion of the clinical evidence from randomized trials.

Author Contributions: W.C., concept and writing; J.D. concept and writing; I.d.H. concept and writing. All authors have read and agreed to the published version of the manuscript.

Funding: None received. Wim Ceelen is a senior clinical researcher from the Fund for Scientific Research-Flanders (FWO).

Conflicts of Interest: The authors declare no conflict of interest.

\section{References}

1. Lurvink, R.J.; Bakkers, C.; Rijken, A.; van Erning, F.N.; Nienhuijs, S.W.; Burger, J.W.; Creemers, G.J.; Verhoef, C.; Lemmens, V.E.; De Hingh, I.H. Increase in the incidence of synchronous and metachronous peritoneal metastases in patients with colorectal cancer: A nationwide study. Eur. J. Surg. Oncol. 2020, 47, 1026-1033. [CrossRef]

2. Koemans, W.J.; Lurvink, R.J.; Grootscholten, C.; Verhoeven, R.H.A.; de Hingh, I.H.; van Sandick, J.W. Synchronous peritoneal metastases of gastric cancer origin: Incidence, treatment and survival of a nationwide Dutch cohort. Gastric Cancer 2021. [CrossRef]

3. Lengyel, E. Ovarian cancer development and metastasis. Am. J. Pathol. 2010, 177, 1053-1064. [CrossRef] [PubMed]

4. Flanagan, M.; Solon, J.; Chang, K.H.; Deady, S.; Moran, B.; Cahill, R.; Shields, C.; Mulsow, J. Peritoneal metastases from extra-abdominal cancer-A population-based study. Eur. J. Surg. Oncol. 2018, 44, 1811-1817. [CrossRef]

5. Lurvink, R.J.; Rijken, A.; Bakkers, C.; Aarts, M.J.; Kunst, P.W.A.; van de Borne, B.E.; van Erning, F.N.; de Hingh, I. Synchronous peritoneal metastases from lung cancer: Incidence, associated factors, treatment and survival: A Dutch population-based study. Clin. Exp. Metastasis 2021, 38, 295-303. [CrossRef] 
6. $\quad$ Franko, J.; Shi, Q.; Meyers, J.P.; Maughan, T.S.; Adams, R.A.; Seymour, M.T.; Saltz, L.; Punt, C.J.A.; Koopman, M.; Tournigand, C.; et al. Prognosis of patients with peritoneal metastatic colorectal cancer given systemic therapy: An analysis of individual patient data from prospective randomised trials from the Analysis and Research in Cancers of the Digestive System (ARCAD) database. Lancet Oncol. 2016, 17, 1709-1719. [CrossRef]

7. Warrick, C. An Improvement on the practice of tapping; whereby that operation, instead of a relief for symptoms, becomes an absolute cure for an ascites, exemplified in the case of Jane Roman; And Recommended to the Consideration of the Royal Society, by Christopher Warrick, of Truro, Surgeon. Philos. Trans. 1744, 43, 12-19.

8. Saxena, A.; Yan, T.D.; Morris, D.L. A critical evaluation of risk factors for complications after cytoreductive surgery and perioperative intraperitoneal chemotherapy for colorectal peritoneal carcinomatosis. World J. Surg. 2010, 34, 70-78. [CrossRef] [PubMed]

9. Chua, T.C.; Yan, T.D.; Zhao, J.; Morris, D.L. Peritoneal carcinomatosis and liver metastases from colorectal cancer treated with cytoreductive surgery perioperative intraperitoneal chemotherapy and liver resection. Ejso 2009, 35, 1299-1305. [CrossRef] [PubMed]

10. Dedrick, R.L.; Myers, C.E.; Bungay, P.M.; DeVita, V.T., Jr. Pharmacokinetic rationale for peritoneal drug administration in the treatment of ovarian cancer. Cancer Treat. Rep. 1978, 62, 1-11. [PubMed]

11. Dedrick, R.L. Theoretical and experimental bases of intraperitoneal chemotherapy. Semin. Oncol. 1985, 12, 1-6.

12. Euler, J.; Prieschi, A.; Wenzl, J.; Sauerman, G.; Klockler, K.; Kretschm, G. Hyperthermic peritoneal perfusion in ascites tumors in rats. Wien. Klin. Wochenschr. 1974, 86, 220-225. [PubMed]

13. Spratt, J.S.; Adcock, R.A.; Muskovin, M.; Sherrill, W.; Mckeown, J. Clinical delivery system for intra-peritoneal hyperthermic chemotherapy. Cancer Res. 1980, 40, 256-260.

14. Bushati, M.; Rovers, K.P.; Sommariva, A.; Sugarbaker, P.H.; Morris, D.L.; Yonemura, Y.; Quadros, C.A.; Somashekhar, S.P.; Ceelen, W.; Dubé, P.; et al. The current practice of cytoreductive surgery and HIPEC for colorectal peritoneal metastases: Results of a worldwide web-based survey of the Peritoneal Surface Oncology Group International (PSOGI). Eur. J. Surg. Oncol. 2018, 44, 1942-1948. [CrossRef]

15. Quénet, F.; Elias, D.; Roca, L.; Goéré, D.; Ghouti, L.; Pocard, M.; Facy, O.; Arvieux, C.; Lorimier, G.; Pezet, D.; et al. Cytoreductive surgery plus hyperthermic intraperitoneal chemotherapy versus cytoreductive surgery alone for colorectal peritoneal metastases (PRODIGE 7): A multicentre, randomised, open-label, phase 3 trial. Lancet Oncol. 2021, 22, 256-266. [CrossRef]

16. Hasovits, C.; Clarke, S. Pharmacokinetics and Pharmacodynamics of Intraperitoneal Cancer Chemotherapeutics. Clin. Pharmacokinet. 2012, 51, 203-224. [CrossRef]

17. Leypoldt, J.K. Solute transport across the peritoneal membrane. J. Am. Soc. Nephrol. 2002, 13 (Suppl. 1), S84-S91. [CrossRef]

18. Butler, T.P.; Grantham, F.H.; Gullino, P.M. Bulk transfer of fluid in the interstitial compartment of mammary tumors. Cancer Res. 1975, 35, 3084-3088. [PubMed]

19. Stylianopoulos, T. The solid mechanics of cancer and strategies for improved therapy. J. Biomech. Eng. 2017, 139. [CrossRef] [PubMed]

20. McGrail, D.J.; McAndrews, K.M.; Brandenburg, C.P.; Ravikumar, N.; Kieu, Q.M.; Dawson, M.R. Osmotic regulation is required for cancer cell survival under solid stress. Biophys. J. 2015, 109, 1334-1337. [CrossRef] [PubMed]

21. Netti, P.A.; Berk, D.A.; Swartz, M.A.; Grodzinsky, A.J.; Jain, R.K. Role of extracellular matrix assembly in interstitial transport in solid tumors. Cancer Res. 2000, 60, 2497-2503. [PubMed]

22. Jain, R.K. Transport of molecules in the tumor interstitium: A review. Cancer Res. 1987, 47, 3039-3051.

23. Young, E.W. Cells, tissues, and organs on chips: Challenges and opportunities for the cancer tumor microenvironment. Integr. Biol. 2013, 5, 1096-1109. [CrossRef]

24. Baker, A.M.; Bird, D.; Lang, G.; Cox, T.R.; Erler, J.T. Lysyl oxidase enzymatic function increases stiffness to drive colorectal cancer progression through FAK. Oncogene 2013, 32, 1863-1868. [CrossRef] [PubMed]

25. Butcher, D.T.; Alliston, T.; Weaver, V.M. A tense situation: Forcing tumour progression. Nat. Rev. Cancer 2009, 9, 108-122. [CrossRef]

26. Steuperaert, M.; Debbaut, C.; Carlier, C.; De Wever, O.; Descamps, B.; Vanhove, C.; Ceelen, W.; Segers, P. A 3D CFD model of the interstitial fluid pressure and drug distribution in heterogeneous tumor nodules during intraperitoneal chemotherapy. Drug Deliv. 2019, 26, 404-415. [CrossRef]

27. Carlier, C.; Mathys, A.; De Jaeghere, E.; Steuperaert, M.; De Wever, O.; Ceelen, W. Tumour tissue transport after intraperitoneal anticancer drug delivery. Int. J. Hyperth. 2017, 33, 534-542. [CrossRef]

28. Cox, T.R. The matrix in cancer. Nat. Rev. Cancer 2021, 21, 217-238. [CrossRef] [PubMed]

29. Hildebrandt, B.; Wust, P.; Ahlers, O.; Dieing, A.; Sreenivasa, G.; Kerner, T.; Felix, R.; Riess, H. The cellular and molecular basis of hyperthermia. Crit. Rev. Oncol. Hematol. 2002, 43, 33-56. [CrossRef]

30. Datta, N.R.; Ordóñez, S.G.; Gaipl, U.S.; Paulides, M.M.; Crezee, H.; Gellermann, J.; Marder, D.; Puric, E.; Bodis, S. Local hyperthermia combined with radiotherapy and-/or chemotherapy: Recent advances and promises for the future. Cancer Treat. Rev. 2015, 41, 742-753. [CrossRef]

31. Los, G.; Sminia, P.; Wondergem, J.; Mutsaers, P.H.A.; Havemen, J.; Huinink, D.T.; Smals, O.; Gonzalezgonzalez, D.; Mcvie, J.G. Optimization of intraperitoneal cisplatin therapy with regional hyperthermia in rats. Eur. J. Cancer 1991, 27, 472-477. [CrossRef] 
32. Pestieau, S.R.; Belliveau, J.F.; Griffin, H.; Stuart, O.A.; Sugarbaker, P.H. Pharmacokinetics of intraperitoneal oxaliplatin: Experimental studies. J. Surg. Oncol. 2001, 76, 106-114. [CrossRef]

33. Jacquet, P.; Averbach, A.; Stuart, O.A.; Chang, D.; Sugarbaker, P.H. Hyperthermic intraperitoneal doxorubicin: Pharmacokinetics, metabolism, and tissue distribution in a rat model. Cancer Chemother. Pharmacol. 1998, 41, 147-154. [CrossRef]

34. Helderman, R.; Löke, D.R.; Verhoeff, J.; Rodermond, H.M.; van Bochove, G.G.W.; Boon, M.; van Kesteren, S.; Garcia Vallejo, J.J.; Kok, H.P.; Tanis, P.J.; et al. The temperature-dependent effectiveness of platinum-based drugs mitomycin-C and 5-FU during hyperthermic intraperitoneal chemotherapy (HIPEC) in colorectal cancer cell lines. Cells 2020, 9, 1775. [CrossRef]

35. Boussios, S.; Moschetta, M.; Karathanasi, A.; Tsiouris, A.K.; Kanellos, F.S.; Tatsi, K.; Katsanos, K.H.; Christodoulou, D.K. Malignant peritoneal mesothelioma: Clinical aspects, and therapeutic perspectives. Ann. Gastroenterol. 2018, 31, 659-669. [CrossRef]

36. Forsythe, S.D.; Sasikumar, S.; Moaven, O.; Sivakumar, H.; Shen, P.; Levine, E.A.; Soker, S.; Skardal, A.; Votanopoulos, K.I. Personalized identification of optimal HIPEC perfusion protocol in patient-derived tumor organoid platform. Ann. Surg. Oncol. 2020, 27, 4950-4960. [CrossRef]

37. Kepenekian, V.; Aloy, M.T.; Magne, N.; Passot, G.; Armandy, E.; Decullier, E.; Sayag-Beaujard, A.; Gilly, F.N.; Glehen, O.; Rodriguez-Lafrasse, C. Impact of hyperthermic intraperitoneal chemotherapy on Hsp27 protein expression in serum of patients with peritoneal carcinomatosis. Cell Stress Chaperones 2013, 18, 623-630. [CrossRef] [PubMed]

38. Grimmig, T.; Moll, E.M.; Kloos, K.; Thumm, R.; Moench, R.; Callies, S.; Kreckel, J.; Vetterlein, M.; Pelz, J.; Polat, B.; et al. Upregulated heat shock proteins after hyperthermic chemotherapy point to induced cell survival mechanisms in affected tumor cells from peritoneal carcinomatosis. Cancer Growth Metastasis 2017, 10, 1179064417730559. [CrossRef] [PubMed]

39. Fujimoto, S.; Kokubun, M.; Shrestha, R.D.; Kobayashi, K.; Kiuchi, S.; Konno, C.; Takahashi, M.; Okui, K. Prevention of scald injury on the peritoneo-serosal surface in advanced gastric cancer patients treated with intraperitoneal hyperthermic perfusion. Int. J. Hyperth. 1991, 7, 543-550. [CrossRef] [PubMed]

40. Yonemura, Y.; de Aretxabala, X.; Fujimura, T.; Fushida, S.; Katayama, K.; Bandou, E.; Sugiyama, K.; Kawamura, T.; Kinoshita, K.; Endou, Y.; et al. Intraoperative chemohyperthermic peritoneal perfusion as an adjuvant to gastric cancer: Final results of a randomized controlled study. Hepatogastroenterology 2001, 48, 1776-1782.

41. Chang, M.; Hou, Z.; Wang, M.; Li, C.; Lin, J. Recent advances in hyperthermia therapy-based synergistic immunotherapy. Adv. Mater. 2021, 33, e2004788. [CrossRef]

42. Minnaar, C.A.; Kotzen, J.A.; Ayeni, O.A.; Vangu, M.D.; Baeyens, A. Potentiation of the abscopal effect by modulated electrohyperthermia in locally advanced cervical cancer patients. Front. Oncol. 2020, 10, 376. [CrossRef] [PubMed]

43. Bear, A.S.; Kennedy, L.C.; Young, J.K.; Perna, S.K.; Mattos Almeida, J.P.; Lin, A.Y.; Eckels, P.C.; Drezek, R.A.; Foster, A.E. Elimination of metastatic melanoma using gold nanoshell-enabled photothermal therapy and adoptive T cell transfer. PLoS ONE 2013, 8, e69073. [CrossRef] [PubMed]

44. Seclì, L.; Fusella, F.; Avalle, L.; Brancaccio, M. The dark-side of the outside: How extracellular heat shock proteins promote cancer. Cell. Mol. Life Sci. 2021, 78, 4069-4083. [CrossRef] [PubMed]

45. Ramanathan, R.; Choudry, H.; Jones, H.; Girgis, M.; Gooding, W.; Kalinski, P.; Bartlett, D.L. Phase II trial of adjuvant dendritic cell vaccine in combination with celecoxib, interferon- $\alpha$, and rintatolimod in patients undergoing cytoreductive surgery and hyperthermic intraperitoneal chemotherapy for peritoneal metastases. Ann. Surg. Oncol. 2021, 1-10. [CrossRef]

46. Franko, J.; Brahmbhatt, R.; Tee, M.; Raman, S.; Ferrel, B.; Gorvet, M.; Andres, M. Cellular immunoprofile of peritoneal environment during a HIPEC procedure. Ann. Surg. Oncol. 2020, 27, 5005-5013. [CrossRef]

47. Van der Speeten, K.; Lemoine, L.; Sugarbaker, P. Overview of the optimal perioperative intraperitoneal chemotherapy regimens used in current clinical practice. Pleura Peritoneum 2017, 2, 63-72. [CrossRef]

48. Helderman, R.; Löke, D.R.; Kok, H.P.; Oei, A.L.; Tanis, P.J.; Franken, N.; Crezee, J. Variation in clinical application of hyperthermic intraperitoneal chemotherapy: A Review. Cancers 2019, 11, 78. [CrossRef]

49. Wisselink, D.D.; Braakhuis, L.L.F.; Gallo, G.; van Grevenstein, W.M.U.; van Dieren, S.; Kok, N.F.M.; de Reuver, P.R.; Tanis, P.J.; de Hingh, I. Systematic review of published literature on oxaliplatin and mitomycin $\mathrm{C}$ as chemotherapeutic agents for hyperthermic intraperitoneal chemotherapy in patients with peritoneal metastases from colorectal cancer. Crit. Rev. Oncol. Hematol. 2019, 142, 119-129. [CrossRef]

50. Levine, E.A.; Votanopoulos, K.I.; Shen, P.; Russell, G.; Fenstermaker, J.; Mansfield, P.; Bartlett, D.; Stewart, J.H. A multicenter randomized trial to evaluate hematologic toxicities after hyperthermic intraperitoneal chemotherapy with oxaliplatin or mitomycin in patients with appendiceal tumors. J. Am. Coll. Surg. 2018, 226, 434-443. [CrossRef] [PubMed]

51. Moaven, O.; Votanopoulos, K.I.; Shen, P.; Mansfield, P.; Bartlett, D.L.; Russell, G.; McQuellon, R.; Stewart, J.H.; Levine, E.A. Health-related quality of life after cytoreductive surgery/HIPEC for mucinous appendiceal cancer: Results of a multicenter randomized trial comparing oxaliplatin and mitomycin. Ann. Surg. Oncol. 2020, 27, 772-780. [CrossRef]

52. Ceelen, W. HIPEC with oxaliplatin for colorectal peritoneal metastasis: The end of the road? Eur. J. Surg. Oncol. 2019, 45, 400-402. [CrossRef] [PubMed]

53. Quenet, F.; Goéré, D.; Mehta, S.S.; Roca, L.; Dumont, F.; Hessissen, M.; Saint-Aubert, B.; Elias, D. Results of two bi-institutional prospective studies using intraperitoneal oxaliplatin with or without irinotecan during HIPEC after cytoreductive surgery for colorectal carcinomatosis. Ann. Surg. 2011, 254, 294-301. [CrossRef] [PubMed] 
54. Rodríguez Silva, C.; Moreno Ruiz, F.J.; Bellido Estévez, I.; Carrasco Campos, J.; Titos García, A.; Ruiz López, M.; González Poveda, I.; Toval Mata, J.A.; Mera Velasco, S.; Santoyo Santoyo, J. Are there intra-operative hemodynamic differences between the Coliseum and closed HIPEC techniques in the treatment of peritoneal metastasis? A retrospective cohort study. World J. Surg. Oncol. 2017, 15, 51. [CrossRef] [PubMed]

55. Leiting, J.L.; Cloyd, J.M.; Ahmed, A.; Fournier, K.; Lee, A.J.; Dessureault, S.; Felder, S.; Veerapong, J.; Baumgartner, J.M.; Clarke, C.; et al. Comparison of open and closed hyperthermic intraperitoneal chemotherapy: Results from the United States hyperthermic intraperitoneal chemotherapy collaborative. World J. Gastrointest. Oncol. 2020, 12, 756-767. [CrossRef]

56. Cianci, S.; Abatini, C.; Fagotti, A.; Chiofalo, B.; Tropea, A.; Biondi, A.; Scambia, G.; Pacelli, F. Hyperthermic intraperitoneal chemotherapy (HIPEC) for peritoneal malignancies using new hybrid CO (2) system: Preliminary experience in referral center. Updates Surg. 2019, 71, 555-560. [CrossRef]

57. Arjona-Sanchez, A.; Aziz, O.; Passot, G.; Salti, G.; Esquivel, J.; Van der Speeten, K.; Piso, P.; Nedelcut, D.S.; Sommariva, A.; Yonemura, Y.; et al. Laparoscopic cytoreductive surgery and hyperthermic intraperitoneal chemotherapy for limited peritoneal metastasis. The PSOGI international collaborative registry. Eur. J. Surg. Oncol. 2020. [CrossRef]

58. Verwaal, V.J.; Bruin, S.; Boot, H.; van Slooten, G.; van Tinteren, H. 8-year follow-up of randomized trial: Cytoreduction and hyperthermic intraperitoneal chemotherapy versus systemic chemotherapy in patients with peritoneal carcinomatosis of colorectal cancer. Ann. Surg. Oncol. 2008, 15, 2426-2432. [CrossRef]

59. Klaver, C.E.L.; Wisselink, D.D.; Punt, C.J.A.; Snaebjornsson, P.; Crezee, J.; Aalbers, A.G.J.; Brandt, A.; Bremers, A.J.A.; Burger, J.W.A.; Fabry, H.F.J.; et al. Adjuvant hyperthermic intraperitoneal chemotherapy in patients with locally advanced colon cancer (COLOPEC): A multicentre, open-label, randomised trial. Lancet Gastroenterol. Hepatol. 2019, 4, 761-770. [CrossRef]

60. Goéré, D.; Glehen, O.; Quenet, F.; Guilloit, J.M.; Bereder, J.M.; Lorimier, G.; Thibaudeau, E.; Ghouti, L.; Pinto, A.; Tuech, J.J.; et al. Second-look surgery plus hyperthermic intraperitoneal chemotherapy versus surveillance in patients at high risk of developing colorectal peritoneal metastases (PROPHYLOCHIP-PRODIGE 15): A randomised, phase 3 study. Lancet Oncol. 2020, 21, 1147-1154. [CrossRef]

61. Rovers, K.P.; Bakkers, C.; Nienhuijs, S.W.; Burger, J.W.A.; Creemers, G.M.; Thijs, A.M.J.; Brandt-Kerkhof, A.R.M.; Madsen, E.V.E.; van Meerten, E.; Tuynman, J.B.; et al. Perioperative systemic therapy vs cytoreductive surgery and hyperthermic intraperitoneal chemotherapy alone for resectable colorectal peritoneal metastases: A phase 2 randomized clinical trial. JAMA Surg. 2021. [CrossRef] [PubMed]

62. Spiliotis, J.; Halkia, E.; Lianos, E.; Kalantzi, N.; Grivas, A.; Efstathiou, E.; Giassas, S. Cytoreductive surgery and HIPEC in recurrent epithelial ovarian cancer: A prospective randomized phase III study. Ann. Surg. Oncol. 2015, 22, 1570-1575. [CrossRef] [PubMed]

63. van Driel, W.J.; Koole, S.N.; Sikorska, K.; Schagen van Leeuwen, J.H.; Schreuder, H.W.R.; Hermans, R.H.M.; de Hingh, I.; van der Velden, J.; Arts, H.J.; Massuger, L.; et al. Hyperthermic intraperitoneal chemotherapy in ovarian cancer. N. Engl. J. Med. 2018, 378, 230-240. [CrossRef] [PubMed]

64. Zivanovic, O.; Chi, D.S.; Zhou, Q.; Iasonos, A.; Konner, J.A.; Makker, V.; Grisham, R.N.; Brown, A.K.; Nerenstone, S.; Diaz, J.P.; et al. Secondary Cytoreduction and Carboplatin Hyperthermic Intraperitoneal Chemotherapy for Platinum-Sensitive Recurrent Ovarian Cancer: An MSK Team Ovary Phase II Study. J. Clin. Oncol. 2021, Jco2100605. [CrossRef]

65. Rassy, E.; Assi, T.; Boussios, S.; Kattan, J.; Smith-Gagen, J.; Pavlidis, N. Narrative review on serous primary peritoneal carcinoma of unknown primary site: Four questions to be answered. Ann. Transl. Med. 2020, 8, 1709. [CrossRef] [PubMed]

66. Koole, S.N.; Kieffer, J.M.; Sikorska, K.; Schagen van Leeuwen, J.H.; Schreuder, H.W.R.; Hermans, R.H.; de Hingh, I.H.; van der Velden, J.; Arts, H.J.; van Ham, M.; et al. Health-related quality of life after interval cytoreductive surgery with or without hyperthermic intraperitoneal chemotherapy (HIPEC) in patients with stage III ovarian cancer. Eur. J. Surg. Oncol. 2021, 47, 101-107. [CrossRef] [PubMed]

67. Koole, S.N.; van Lieshout, C.; van Driel, W.J.; van Schagen, E.; Sikorska, K.; Kieffer, J.M.; Schagen van Leeuwen, J.H.; Schreuder, H.W.R.; Hermans, R.H.; de Hingh, I.H.; et al. Effectiveness of Interval Cytoreductive Surgery with Hyperthermic Intraperitoneal Chemotherapy in Stage III Ovarian Cancer on the Basis of a Randomized Phase III Trial. J. Clin. Oncol. 2019, 37, 2041-2050. [CrossRef]

68. Armstrong, D.K.; Alvarez, R.D.; Bakkum-Gamez, J.N.; Barroilhet, L.; Behbakht, K.; Berchuck, A.; Berek, J.S.; Chen, L.M.; Cristea, M.; DeRosa, M.; et al. NCCN Guidelines Insights: Ovarian Cancer, Version 1.2019. J. Natl. Compr. Cancer Netw. JNCCN 2019, 17, 896-909. [CrossRef]

69. Boussios, S.; Pavlidis, N. Ovarian cancer: State of the art and perspectives of clinical research. Ann. Transl. Med. 2020, 8, 1702. [CrossRef]

70. Lim, M.C.; Chang, S.-J.; Yoo, H.J.; Nam, B.-H.; Bristow, R.; Park, S.-Y. Randomized trial of hyperthermic intraperitoneal chemotherapy (HIPEC) in women with primary advanced peritoneal, ovarian, and tubal cancer. J. Clin. Oncol. 2017, 35, 5520. [CrossRef]

71. Koole, S.; van Stein, R.; Sikorska, K.; Barton, D.; Perrin, L.; Brennan, D.; Zivanovic, O.; Mosgaard, B.J.; Fagotti, A.; Colombo, P.E.; et al. Primary cytoreductive surgery with or without hyperthermic intraperitoneal chemotherapy (HIPEC) for FIGO stage III epithelial ovarian cancer: OVHIPEC-2, a phase III randomized clinical trial. Int. J. Gynecol. Cancer 2020, 30, 888-892. [CrossRef]

72. Farrell, R.; Burling, M. HIPEC: Turning up the heat on ovarian cancer. Aust. N. Z. J. Obstet. Gynaecol. 2021, 61, 11-15. [CrossRef] [PubMed] 
73. Verwaal, V.J.; van Ruth, S.; de Bree, E.; van Sloothen, G.W.; van Tinteren, H.; Boot, H.; Zoetmulder, F.A. Randomized trial of cytoreduction and hyperthermic intraperitoneal chemotherapy versus systemic chemotherapy and palliative surgery in patients with peritoneal carcinomatosis of colorectal cancer. J. Clin. Oncol. 2003, 21, 3737-3743. [CrossRef] [PubMed]

74. Flood, M.; Narasimhan, V.; Waters, P.; Ramsay, R.; Michael, M.; Warrier, S.; Heriot, A. Survival after cytoreductive surgery and hyperthermic intraperitoneal chemotherapy for colorectal peritoneal metastases: A systematic review and discussion of latest controversies. Surgeon 2020. [CrossRef] [PubMed]

75. Chua, T.C.; Yan, T.D.; Saxena, A.; Morris, D.L. Should the treatment of peritoneal carcinomatosis by cytoreductive surgery and hyperthermic intraperitoneal chemotherapy still be regarded as a highly morbid procedure? A systematic review of morbidity and mortality. Ann. Surg. 2009, 249, 900-907. [CrossRef] [PubMed]

76. Nagourney, R.A.; Evans, S.; Tran, P.H.; Nagourney, A.J.; Sugarbaker, P.H. Colorectal cancer cells from patients treated with FOLFOX or CAPOX are resistant to oxaliplatin. Eur. J. Surg. Oncol. 2021, 47, 738-742. [CrossRef]

77. Ubink, I.; Bolhaqueiro, A.C.F.; Elias, S.G.; Raats, D.A.E.; Constantinides, A.; Peters, N.A.; Wassenaar, E.C.E.; de Hingh, I.; Rovers, K.P.; van Grevenstein, W.M.U.; et al. Organoids from colorectal peritoneal metastases as a platform for improving hyperthermic intraperitoneal chemotherapy. Br. J. Surg. 2019, 106, 1404-1414. [CrossRef]

78. Rovers, K.P.; Simkens, G.A.; Punt, C.J.; van Dieren, S.; Tanis, P.J.; de Hingh, I.H. Perioperative systemic therapy for resectable colorectal peritoneal metastases: Sufficient evidence for its widespread use? A critical systematic review. Crit. Rev. Oncol. Hematol. 2017, 114, 53-62. [CrossRef]

79. Waite, K.; Youssef, H. The Role of Neoadjuvant and Adjuvant Systemic Chemotherapy with Cytoreductive Surgery and Heated Intraperitoneal Chemotherapy for Colorectal Peritoneal Metastases: A Systematic Review. Ann. Surg. Oncol. 2017, 24, 705-720. [CrossRef]

80. Repullo, D.J.; Barbois, S.; Leonard, D.; Bohlok, A.; Van den Audenaeren, E.T.; Hendlisz, A.; Van den Eynde, M.; Donckier, V.; Kartheuser, A.; Liberale, G. The absence of benefit of perioperative chemotherapy in initially resectable peritoneal metastases of colorectal cancer origin treated with complete cytoreductive surgery and hyperthermic intraperitoneal chemotherapy: A retrospective analysis. Eur. J. Surg. Oncol. 2021. [CrossRef]

81. Rovers, K.P.; Bakkers, C.; Simkens, G.; Burger, J.W.A.; Nienhuijs, S.W.; Creemers, G.M.; Thijs, A.M.J.; Brandt-Kerkhof, A.R.M.; Madsen, E.V.E.; Ayez, N.; et al. Perioperative systemic therapy and cytoreductive surgery with HIPEC versus upfront cytoreductive surgery with HIPEC alone for isolated resectable colorectal peritoneal metastases: Protocol of a multicentre, open-label, parallel-group, phase II-III, randomised, superiority study (CAIRO6). BMC Cancer 2019, 19, 390.

82. Goere, D.; Glehen, O.; Quenet, F.; Ducreux, M.; Guilloit, J.-M.; Texier, M.; Benhamou, E.; Elias, D. BIG-RENAPE.; PRODIGE, Results of a randomized phase 3 study evaluating the potential benefit of a second-look surgery plus HIPEC in patients at high risk of developing colorectal peritoneal metastases (PROPHYLOCHIP- NTC01226394). J. Clin. Oncol. 2018, 36, 3531. [CrossRef]

83. Klaver, C.E.L.; Wisselink, D.D.; Punt, C.J.A.; Snaebjornsson, P.; Crezee, J.; Aalbers, A.; Bemelman, W.A.; Brandt, A.; Bremers, A.; Burger, J.W.A.; et al. Adjuvant HIPEC in patients with colon cancer at high risk of peritoneal metastases: Primary outcome of the COLOPEC multicenter randomized trial. J. Clin. Oncol. 2019, 37, 482. [CrossRef]

84. Ripley, R.T.; Davis, J.L.; Kemp, C.D.; Steinberg, S.M.; Toomey, M.A.; Avital, I. Prospective randomized trial evaluating mandatory second look surgery with HIPEC and CRS vs. standard of care in patients at high risk of developing colorectal peritoneal metastases. Trials 2010, 11, 1-8. [CrossRef]

85. Pai, R.K.; Longacre, T.A. Appendiceal mucinous tumors and pseudomyxoma peritonei-Histologic features, diagnostic problems, and proposed classification. Adv. Anat. Pathol. 2005, 12, 291-311. [CrossRef]

86. Panarelli, N.C.; Yantiss, R.K. Mucinous neoplasms of the appendix and peritoneum. Arch. Pathol. Lab. Med. 2011, 135, 1261-1268. [CrossRef]

87. Legue, L.M.; Creemers, G.J.; de Hingh, I.; Lemmens, V.; Huysentruyt, C.J. Review: Pathology and its clinical relevance of mucinous appendiceal neoplasms and pseudomyxoma peritonei. Clin Colorectal Cancer 2019, 18, 1-7. [CrossRef]

88. Smeenk, R.M.; Verwaal, V.J.; Zoetmulder, F.A.N. Pseudomyxoma peritonei. Cancer Treat. Rev. 2007, 33, 138-145. [CrossRef]

89. Sugarbaker, P.H.; Chang, D. Results of treatment of 385 patients with peritoneal surface spread of appendiceal malignancy. Ann. Surg. Oncol. 1999, 6, 727-731. [CrossRef]

90. Elias, D.; Honore, C.; Ciuchendea, R.; Billard, V.; Raynard, B.; Lo Dico, R.; Dromain, C.; Duvillard, P.; Goere, D. Peritoneal pseudomyxoma: Results of a systematic policy of complete cytoreductive surgery and hyperthermic intraperitoneal chemotherapy. Br. J. Surg. 2008, 95, 1164-1171. [CrossRef]

91. Smeenk, R.M.; Verwaal, V.J.; Antonini, N.; Zoetmulder, F.A.N. Survival analysis of pseudomyxoma peritonei patients treated by cytoreductive surgery and hyperthermic intraperitoneal chemotherapy. Ann. Surg. 2007, 245, 104-109. [CrossRef] [PubMed]

92. Wang, Y.S.; Gong, C.Y.; Yang, L.; Wu, Q.J.; Shi, S.A.; Shi, H.S.; Qian, Z.Y.; Wei, Y.Q. 5-FU-hydrogel inhibits colorectal peritoneal carcinomatosis and tumor growth in mice. BMC Cancer 2010, 10, 1-8. [CrossRef]

93. Kusamura, S.; Barretta, F.; Yonemura, Y.; Sugarbaker, P.H.; Moran, B.J.; Levine, E.A.; Goere, D.; Baratti, D.; Nizri, E.; Morris, D.L.; et al. The role of hyperthermic intraperitoneal chemotherapy in pseudomyxoma peritonei After cytoreductive surgery. JAMA Surg. 2021, 156, e206363. [CrossRef] [PubMed]

94. Sugarbaker, P.H. New standard of care for appendiceal epithelial neoplasms and pseudomyxoma peritonei syndrome? Lancet Oncology 2006, 7, 69-76. [CrossRef] 
95. Miner, T.J.; Shia, J.R.; Jaques, D.P.; Klimstra, D.S.; Brennan, M.F.; Coit, D.G. Long-term survival following treatment of pseudomyxoma peritonei-An analysis of surgical therapy. Ann. Surg. 2005, 241, 300-308. [CrossRef] [PubMed]

96. Kobayashi, D.; Kodera, Y. Intraperitoneal chemotherapy for gastric cancer with peritoneal metastasis. Gastric Cancer 2017, 20, 111-121. [CrossRef] [PubMed]

97. Feingold, P.L.; Kwong, M.L.; Davis, J.L.; Rudloff, U. Adjuvant intraperitoneal chemotherapy for the treatment of gastric cancer at risk for peritoneal carcinomatosis: A systematic review. J. Surg. Oncol. 2017, 115, 192-201. [CrossRef]

98. Yan, T.D.; Black, D.; Sugarbaker, P.H.; Zhu, J.Q.; Yonemura, Y.; Petrou, G.; Morris, D.L. A systematic review and meta-analysis of the randomized controlled trials on adjuvant intraperitoneal chemotherapy for resectable gastric cancer. Ann. Surg. Oncol. 2007, 14, 2702-2713. [CrossRef]

99. Desiderio, J.; Chao, J.; Melstrom, L.; Warner, S.; Tozzi, F.; Fong, Y.; Parisi, A.; Woo, Y. The 30-year experience-A meta-analysis of randomised and high-quality non-randomised studies of hyperthermic intraperitoneal chemotherapy in the treatment of gastric cancer. Eur. J. Cancer 2017, 79, 1-14. [CrossRef]

100. van der Kaaij, R.T.; Wassenaar, E.C.E.; Koemans, W.J.; Sikorska, K.; Grootscholten, C.; Los, M.; Huitema, A.; Schellens, J.H.M.; Veenhof, A.; Hartemink, K.J.; et al. Treatment of PERItoneal disease in Stomach Cancer with cytOreductive surgery and hyperthermic intraPEritoneal chemotherapy: PERISCOPE I initial results. Br. J. Surg. 2020, 107, 1520-1528. [CrossRef]

101. Yan, T.D.; Welch, L.; Black, D.; Sugarbaker, P.H. A systematic review on the efficacy of cytoreductive surgery combined with perioperative intraperitoneal chemotherapy for diffuse malignancy peritoneal mesothelioma. Ann. Oncol. 2007, 18, 827-834. [CrossRef] [PubMed]

102. Liu, Y.; Yonemura, Y.; Levine, E.A.; Glehen, O.; Goere, D.; Elias, D.; Morris, D.L.; Sugarbaker, P.H.; Tuech, J.J.; Cashin, P.; et al. Cytoreductive surgery plus hyperthermic intraperitoneal chemotherapy for peritoneal metastases from a small bowel adenocarcinoma: Multi-institutional experience. Ann. Surg. Oncol. 2018, 25, 1184-1192. [CrossRef] [PubMed]

103. Subbiah, V.; Lamhamedi-Cherradi, S.E.; Cuglievan, B.; Menegaz, B.A.; Camacho, P.; Huh, W.; Ramamoorthy, V.; Anderson, P.M.; Pollock, R.E.; Lev, D.C.; et al. Multimodality treatment of desmoplastic small round cell tumor: Chemotherapy and complete cytoreductive surgery improve patient survival. Clin. Cancer Res. 2018, 24, 4865-4873. [CrossRef] [PubMed]

104. Horsman, M.R.; Overgaard, J. Hyperthermia: A potent enhancer of radiotherapy. Clin. Oncol. 2007, 19, 418-426. [CrossRef] [PubMed]

105. Gardner, S.N. A mechanistic, predictive model of dose-response curves for cell cycle phase-specific and -nonspecific drugs. Cancer Res. 2000, 60, 1417-1425. [PubMed]

106. Dakwar, G.R.; Shariati, M.; Willaert, W.; Ceelen, W.; De Smedt, S.C.; Remaut, K. Nanomedicine-based intraperitoneal therapy for the treatment of peritoneal carcinomatosis-Mission possible? Adv. Drug Deliv. Rev. 2017, 108, 13-24. [CrossRef] [PubMed]

107. Zhu, L.; Xu, Y.; Shan, Y.; Zheng, R.; Wu, Z.; Ma, S. Intraperitoneal perfusion chemotherapy and whole abdominal hyperthermia using external radiofrequency following radical D2 resection for treatment of advanced gastric cancer. Int. J. Hyperth. 2019, 36, 403-407. [CrossRef]

108. McCabe-Lankford, E.; McCarthy, B.; Berwick, M.A.; Salafian, K.; Galarza-Paez, L.; Sarkar, S.; Sloop, J.; Donati, G.; Brown, A.J.; Levi-Polyachenko, N. Binding of targeted semiconducting photothermal polymer nanoparticles for intraperitoneal detection and treatment of colorectal cancer. Nanotheranostics 2020, 4, 107-118. [CrossRef]

109. Beck, M.; Ghadjar, P.; Weihrauch, M.; Burock, S.; Budach, V.; Nadobny, J.; Sehouli, J.; Wust, P. Regional hyperthermia of the abdomen, a pilot study towards the treatment of peritoneal carcinomatosis. Radiat. Oncol. 2015, 10, 157. [CrossRef]

110. Kok, H.P.; Beck, M.; Löke, D.R.; Helderman, R.; van Tienhoven, G.; Ghadjar, P.; Wust, P.; Crezee, H. Locoregional peritoneal hyperthermia to enhance the effectiveness of chemotherapy in patients with peritoneal carcinomatosis: A simulation study comparing different locoregional heating systems. Int. J. Hyperth. 2020, 37, 76-88. [CrossRef]

111. Löke, D.R.; Helderman, R.; Rodermond, H.M.; Tanis, P.J.; Streekstra, G.J.; Franken, N.A.P.; Oei, A.L.; Crezee, J.; Kok, H.P. Demonstration of treatment planning software for hyperthermic intraperitoneal chemotherapy in a rat model. Int. J. Hyperth. 2021, 38, 38-54. [CrossRef]

112. McCabe-Lankford, E.; Peterson, M.; McCarthy, B.; Brown, A.J.; Terry, B.; Galarza-Paez, L.; Levi-Polyachenko, N. Murine models of intraperitoneal perfusion for disseminated colorectal cancer. J. Surg. Res. 2019, 233, 310-322. [CrossRef]

113. Liesenfeld, L.F.; Hillebrecht, H.C.; Klose, J.; Schmidt, T.; Schneider, M. Impact of perfusate concentration on hyperthermic intraperitoneal chemotherapy efficacy and toxicity in a rodent model. J. Surg. Res. 2020, 253, 262-271. [CrossRef]

114. Schuitevoerder, D.; Sherman, S.K.; Izquierdo, F.J.; Eng, O.S.; Turaga, K.K. Assessment of the surgical workforce pertaining to cytoreductive surgery and hyperthermic intraperitoneal chemotherapy in the United States. Ann. Surg. Oncol. 2020, 27, 3097-3102. [CrossRef]

115. Ceelen, W.P. Clinical research in surgery: Threats and opportunities. Eur. Surg. Res. 2014, 53, 95-107. [CrossRef]

116. Ceelen, W.; Ramsay, R.G.; Narasimhan, V.; Heriot, A.G.; De Wever, O. Targeting the tumor microenvironment in colorectal peritoneal metastases. Trends Cancer 2020, 6, 236-246. [CrossRef]

117. Harvin, J.A.; Zarzaur, B.L.; Nirula, R.; King, B.T.; Malhotra, A.K. Alternative clinical trial designs. Trauma Surg. Acute Care Open 2020, 5, e000420. [CrossRef] 